\title{
Artificial Algae Algorithm with Multi-Light Source Movement for Economic Dispatch of Thermal Generation
}

\author{
Hafiz Muhammad Awais ${ }^{1 a}$, Tahir Nadeem Malik², Aftab Ahmad ${ }^{1 b}$ \\ RECEIVED ON 22.01.2019， ACCEPTED ON 03.05.2019
}

\begin{abstract}
Economic Dispatch (ED) is one of the major concerns for the efficient and economical operation of the modern power system. Actual ED problem is non-convex in nature due to Ramp Rate Limits (RRL), Valve-Point Loading Effects (VPLE), and Prohibited Operating Zones (POZs). It is generally converted into a convex problem as mathematical programming based approaches cannot handle the non-convex cost functions except dynamic programming, which also suffers from the curse of dimensionality. Heuristic techniques are potential solution methodologies for solving the non-convex ED problem. Artificial Algae Algorithm (AAA), a recent meta-heuristic optimization approach showed remarkable results on certain MATLAB benchmark functions but its application on industrial problem such as ED is yet to be explored. In this paper, AAA is used to investigate convex and non-convex ED problem due to valve-point effects and POZs while considering the transmission losses. The robustness and effectiveness of the proposed approach are validated by implementing it on IEEE standard test systems $(3,6,13$ and 40 unit Test Systems), which are widely addressed in the literature. The simulation results are promising when compared with other well-known evolutionary algorithms, showing the potential and stability of this algorithm.
\end{abstract}

Key Words: $\quad$ Artificial Algae Algorithm, Artificial Intelligence, Economic Load Dispatch, Metaheuristic Techniques, Optimization Techniques, Power System Operational Planning.

\section{INTRODUCTION}

$\mathrm{E}$ lectrical Power Systems assume a key role in a country's economy. Efficient and optimum operational planning is necessary to cope with the limited energy resources, increased fuel-cost, and ever-growing energy demand. In the recent years, power system operational planning and control have become extremely complicated due to the increased penetration of electricity markets and integration of renewable networks. Solving the issues related to Economic Dispatch (ED) is a vital step in operational planning of a power system. It is a generation allocation problem. The main objective of ED problem is to minimize the generation cost of the generating units while satisfying equality and inequality constraints associated with the system [1].

Generally, ED problem can be classified into static and dynamic economic dispatch problem depending upon the load profile. In static ED problem, the load curve remains straight for the whole time interval under consideration and consequently load demand remains constant. While in dynamic ED problem, the time interval is divided into equal sub-intervals and load demand varies for each subinterval making the problem a multi-stage dynamic optimization problem. Emission constraints of thermal generating stations

\footnotetext{
${ }^{1}$ Department of Electrical Engineering, University of Engineering \& Technology Taxila, Pakistan. Email: ${ }^{a}$ awaissarfraz1@gmail.com (Corresponding author), ${ }_{\text {baftab.ahmad@uettaxila.edu.pk }}$

${ }^{2}$ Faculty of Electrical Engineering, HITEC University, Taxila, Pakistan. Email: tahir.nadeem @ hitecuni.edu.pk

This is an open access article published by Mehran University of Engineering and Technology, Jamshoro under CC BY 4.0 International License. 
can also be incorporated resulting in a multi-objective economic emission dispatch problem. In practice, many real-time factors like usage of different types of fuels, remote location of generating stations, real-time operational limitations, up and down time of thermal generators further complicates the ED problem. In Multi area ED problem, the tie line constraint must be taken into consideration because the congestion of transmission lines greatly affects the power system planning \& operational cost [2].

In traditional ED problem, the fuel costs of generating units are addressed by quadratic functions which are smooth, convex and differentiable. Various classical and numerical optimization techniques have been widely used in literature to solve the convex ED problem such as lambda iteration [3], LaGrange relaxation [4], quadratic programming [5], interior point technique [6], linear programming and dynamic programming [1]. Although this convex and differentiable formulation of ED can be solved with much ease, it is impractical because the presence of real-world constraints such as Prohibited Operating Zones (POZs), ramp rate limits, and valve point effects make the objective function non-convex, non-smooth and non-differentiable. In general, mathematical programming based approaches cannot handle the non-convex cost fuel cost functions except dynamic programming, which also suffers from the curse of dimensionality.

Evolutionary and metaheuristic techniques are potential solution methodologies for non-convex ED problem due to their inherent ability to be independent of differentiability and continuity of the objective function. Recent Evolutionary approaches which have been widely utilized to address ED problem are: Differential Evolution (DE) [7], Particle Swarm Optimization (PSO) [8], Modified Artificial Bee Colony (MABC) [9], Hybrid GA-PS-SQP [10], New Global Particle Swarm Optimization (NGPSO) [11], Shuffled Differential Evolution (SDE) [12], MothFlame Optimizer [13], Harmony Search (HS) [14], Hybrid Big Bang-Big Crunch (HBB-BC) [15], QuasiOppositional Teaching Learning Based Optimization (QOSLTLBO) [16], Chaotic Krill-Herd algorithm (CKH) [17], Modified Water Cycle approach [18],
Hybrid Cuckoo Search technique [19], Hybrid DE-FA algorithm [20], Chaotic Teacher Learner Based Optimization (CTLBO) [21], Modified Symbiotic Organisms Search Algorithm (MSOSA) [22], Tournament-based Harmony Search (THS) [23], Improved Grey Wolf optimizer (IGWO) [24], Hybrid Chemical Reaction Optimization (HCRO) [25], Diffusion Particle Optimization (DPO) [26], Chaotic Bat Algorithm (CBA) [27], Kinetic Gas Molecular Optimization (KGMO) [28], Orthogonal Learning Competitive Swarm Optimizer (OLCSO) [29].

Artificial Algae Algorithm (AAA) is a relatively recent population-based evolutionary approach inspired by the natural living behaviors of microalgae and being used to solve uni-modal and multimodal functions. A practical design optimization case study and MATLAB benchmark functions have been used previously to test the efficiency of the AAA [30]. The IEEE CEC'05 function set was used as benchmark functions and AAA gave successful results over various dimensions of the IEEE suite. A pressurevessel design problem, which is among the extensively addressed optimization problems, was utilized as a sample real-world design problem to verify the effectiveness of the algorithm. Results obtained from these case studies suggest that AAA is a stable approach having balanced local and global search qualifications. The promising results of AAA give the motivation to use this technique for solving a practical engineering problem, since this technique has not been used for the ED problem yet. The ED of thermal generating units using AAA is presented in this paper. Both non-convex and convex problems are solved and the algorithm performance is tested on IEEE standard test systems (3, 6, 13 and 40 unit test systems). The simulation results show that AAA provides superior results when compared with other evolutionary techniques reported in the literature.

The remainder of this paper is structured as follows. Mathematical formulation of the ED problem is presented in Section 2. Section 3 describes the basic structure of AAA. Section 4 shows the implementation of AAA on standard IEEE test systems. The experimental results are presented and analyzed in Section 5. The conclusion is outlined in Section 6. 


\section{ED PROBLEM FORMULATION}

The main objective of ED problem is to schedule the output power of each generating unit so that the overall production cost is minimized and the equality, inequality, and various operating constraints are satisfied. The problem of minimizing the overall fuel cost can be mathematically expressed as [31]:

Minimize $\mathrm{F}_{\text {Total }}=\sum_{\mathrm{j}=1}^{\mathrm{D}} \mathrm{F}_{\mathrm{j}}\left(\mathrm{P}_{\mathrm{j}}\right)$

where, $F_{\text {Total }}$ is the overall fuel cost of production, $P_{j}$ is the real power generation of jth generating unit and $F_{j}\left(P_{j}\right)$ is the production cost of jth generator and $D$ represents the number of generating units.

Based on the nature of objective function, the Economic Dispatch (ED) Problem can be predominantly categorized into convex and nonconvex ED problem. The convex ED problem is generally designed by a quadratic fuel cost function [31]. For the jth generating unit, the expression is as follows:

$F_{j}\left(P_{j}\right)=\alpha_{j} P_{j}^{2}+\beta_{j} P_{j}+\gamma_{j}$

where $\alpha_{\mathrm{j}}, \beta_{\mathrm{j}}, \gamma_{\mathrm{j}}$ denote fuel cost coefficients of $\mathrm{jth}$ generating unit in $\$ / \mathrm{MW}^{2} \mathrm{~h}, \quad \$ / \mathrm{MWh}$ and $\$ / \mathrm{h}$ respectively.

In general, the active power output of the thermal generating units is controlled by using multiple valves for fuel input. The sudden opening and closing of these valves result in the inclusion of discontinuous and non-differential points in the fuel cost curve of thermal units making it non-smooth and non-convex. This phenomenon is referred to as valve-point loading effect [1]. This non-convex behavior of thermal generating units in the presence of multiple valves is modeled by the superposition of a sinusoidal function with the original objective function as follows:

$F_{j}\left(P_{j}\right)=\alpha_{j} P_{j}^{2}+\beta_{j} P_{j}+\gamma_{j}+\mid e_{j} \times \sin \left(f_{j} \times\left(P_{j}^{L B}-\right.\right.$ $\left.\left.P_{j}\right)\right) \mid$ where, $e_{j}$ and $f_{j}$ are the fuel cost coefficients of jth generating unit with Valve-Point Effect (VPE) and $\mathrm{P}_{\mathrm{j}}^{\mathrm{LB}}$ is the minimum active power generation limit of jth generating unit.

ED is considered as a multi-constrained and hard optimization problem. The active power balance constraint, Prohibited Operating Zones (POZs), power generation limits, transmission losses and Valve-Point Effects (VPEs) are taken into account.

The equality constraint conditions that the total generated power must be equivalent to the sum of load demand and transmission losses. It is expressed mathematically as follows:

$\sum_{\mathrm{j}=1}^{\mathrm{D}} \mathrm{P}_{\mathrm{j}}=\mathrm{P}_{\text {Demand }}+P_{T_{\_} \text {Loss }}$

where, $P_{\text {Demand }}$ denotes the total load demand and $P_{T \_ \text {Loss }}$ is the total transmission loss of the system.

The real power component generated by the generators should lie between $\mathrm{P}_{\mathrm{j}}^{\mathrm{LB}}$ and $\mathrm{P}_{\mathrm{j}}^{\mathrm{UB}}$ (MW) so that:

$P_{j}^{L P}<P_{j}<P_{j}^{U P}, j=1,2,3, \ldots, D$

Transmission losses cannot be neglected because the center of load is distant from the generating plants. They are addressed as follows by using the $\beta-$ coefficient method [28]:

$\mathrm{P}_{\mathrm{T}_{-} \text {Loss }}=\sum_{\mathrm{h}=1}^{\mathrm{D}} \sum_{\mathrm{j}=1}^{\mathrm{D}} \mathrm{P}_{\mathrm{h}} \beta_{\mathrm{hj}} \mathrm{P}_{\mathrm{j}}+\sum_{\mathrm{j}=1}^{\mathrm{D}} \beta_{0 \mathrm{j}} \mathrm{P}_{\mathrm{j}}+\beta_{00}$

where $\beta_{\mathrm{ij}}, \beta_{0 \mathrm{j}}$ and $\beta_{00}$ represents the loss coefficients.

To study the economic aspect of the generator scheduling problem, it has been assumed in literature that the variation in production capacity of thermal generators follows a step response and power output of these generators can be regulated instantly. Although these assumptions help us solve the ED problem with much ease, they actually contradict the actual operational characteristics of thermal generators. An acceptable and realistic approach to model the generators state and production changes is to consider the long startup and shutdown processes of thermal generators and use the ramp functions. Due to the physical limitation of generating units, the sudden 
and drastic changes in the generator output are prohibited. These can be mathematically described as follows:

$P_{j, t}-P_{j(t-1)} \leq U R L_{j}, j=1,2,3, \cdots, D$

$P_{j,(t-1)}-P_{j, t} \leq D R L_{j}, \quad j=1,2,3, \cdots, D$

where $U R L_{j}$ and $D R L_{j}$ indicates the up and down ramp limits. $P_{j, t}$ and $P_{j(t-1)}$ denotes the power output at current and previous interval. The integration of ramp rate constraint in ED of thermal generators makes the problem a multistage non-convex dynamic optimization problem.

In practice, associated auxiliaries or the faults in the machines prohibit generating units from operating in some regions, which are called prohibited operating zones of the generators [22].

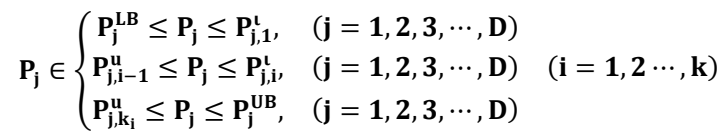

where $i_{j}$ denotes the number of prohibited zones of $j t h$ generating unit. $\mathrm{P}_{\mathrm{j}, \mathrm{i}}^{\mathrm{u}}$ and $\mathrm{P}_{\mathrm{j}, \mathrm{i}}^{\mathrm{l}}$ are the upper and lower limits of ith prohibited operating zone of jth generator, respectively.

\section{AN ESSENTIAL BACKGROUND FOR APPLICATION IN ED PROBLEM}

\subsection{Algae}

Algae belong to a distinct class of photosynthetic species called eukaryotes. Algae have a discrete nucleus and chloroplasts which contains a green pigment called chlorophyll. They have the ability to synthesize their own food using $\mathrm{CO}_{2}$ and $\mathrm{H}_{2} \mathrm{O}$ in the presence of sunlight. They are highly adaptive to the changing and extreme environments like brine lakes and hot springs. The population dynamics of microalgae is mainly dependent upon two processes: growth process and loss process [32]. Nutrient uptake and photosynthesis are key factors affecting the growth processes while the loss processes include grazing, sedimentation (settling in the bottom), parasitism, competition, washout and eventually the death of microalgae. The growth rate of microalgae is the balance between procreation and loss rate. Inertial resistance of the fluid and viscous drag restricts the accelerated movement of an algal colony. Viscous drag force is the rearward exerted pressure by the fluid particles adhering to the exterior of algal cells due to their movement in the viscous fluid.

\subsection{Algal growth characteristics}

The specific growth rate of microalgae biomass are determined from the result of Batch tests. The following equation is used to address the growth rate of algae per unit of biomass:

$\frac{\mathrm{dX}}{\mathrm{dt}}=\mu \mathrm{X}$

where $X$ is the algal biomass concentration $(m g / L)$, $d X / d t$ represents the rate of change of microalgae biomass, $t$ is the time and $\mu$ is the specific rate of growth. Under adequate illumination and a specified temperature, a typical algae growth characteristic of an algal batch in the presence of appropriate supply of $\mathrm{CO}_{2}$ and other nutrients is represented by Fig. 1.

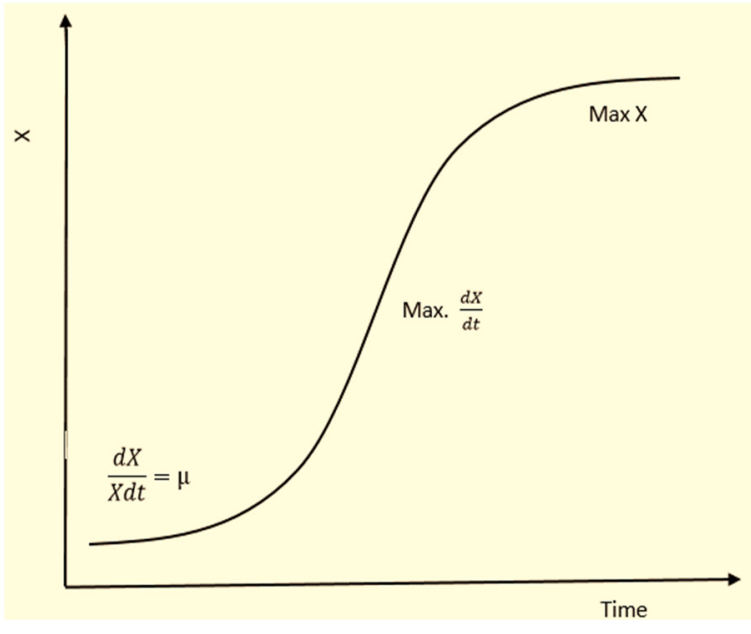

FIG. 1: TYPICAL GROWTH CHARACTERISTICS OF MICROALGAE [30]

As seen from the Fig.1, when the algal cell concentration is low and mutual-shading is assumed to be negligible, growth rate increases exponentially and specific growth rate $(\mu)$ is a constant. For a high 
intensity of incident illumination, if the concentration of algal cells is low and they are sustained at above sunlight saturation level, the exponential growth behavior may continue despite mutual shading. As the concentration of algal cell rises and light absorbance rate gradually approaches $100 \%$, the increase in the quantity of cells is reflected by a linear behavior and $\mathrm{dX} / \mathrm{dt}$ is constant. As the algal cell concentration rises and absorbance rate gradually approaches $100 \%$, the increase in the quantity of cells is reflected by a linear behavior and $\mathrm{dX} / \mathrm{dt}$ is constant. Afterwards, a compensation point will reach where the quantity of algal cells will be maximum and the effective illumination will approach a specific value.

Monod function is used to address the biological growth process of microalgae. Monod function relates specific growth rate $(\mu)$ and substrate concentration.

$\mu=\frac{\mu, \max _{\mathrm{c}} \mathrm{F}_{\mathrm{c}}}{\mathrm{K}_{\mathrm{s}}+\mathrm{F}_{\mathrm{c}}}$

Here $\mu$ indicates the specific growth-rate of algae colonies, $\mu_{\max }$ indicates maximum specific growthrate (1/Time) and it is assumed to be 1 (according to mass conservation principle), and $\mathrm{k}_{\mathrm{s}}$ represents the substrate half-saturation constant (Mass/Volume). It is calculated as change in growth at semi nutrient condition of the colony and $\mathrm{F}_{\mathrm{C}}$ is the concentration of nutrient at time $t$, which is actually the objective fitness value in time $t$.

\subsection{Variation in Light Intensity}

Light intensity is generally measured as solar irradiance which is expressed as the power per unit area or the number of energy photons ( $\mu$ Einstein/ $\mathrm{m}^{2} \mathrm{~s} ; 1$ Einstein $\approx 6 \times 10^{23}$ Photons). Light penetration is restricted by the large amounts of pigments present in microalgae due to their photosynthetic nature [33]. Algal growth is usually limited by the light intensity and is confronted with the complications of light harvesting \& attenuation capacity problems. Light intensity is subjected to reduce exponentially as it penetrates through the liquid surface. This exponential behavior make sure that even considerable changes in the solar irradiance will have negligible effect on depth of the light penetration through the liquid. So, light limited algal bio-mass production ratio will be roughly constant [34].

\subsection{Changes in environmental conditions}

Variations in liquid composition, temperature of the surroundings and sunlight intensity individually or together in combination have a significant effect on the growth characteristics of microalgae. So, algae have altered metabolic properties under different setting of temperature and light intensity.

\subsection{Artificial Algae Algorithm}

Artificial algae corresponds to search space solution by mimicking the behavior of microalgae. Like real microalgae, artificial algae can reproduce by mitotic division phenomena, they are highly adaptive to the surrounding conditions and can change the dominating species depending upon the light and nutrient conditions. They also swim helically in the liquid toward the light source for photosynthesis. Thus the algorithm is composed of three main steps called "Helical Movement", "Evolutionary phase" and "Adaptation". Algae cells are the main species/character/spirit in this algorithm. The entire population consists of algae colonies and a single algae colony is composed of a cluster of cells existing together. When a single cell reproduces by the mitotic division to form two identical daughter cells, they live together and when these two algal cells further reproduce, the four new cells live adjacently and so on. In this way, an algae colony performs similar to a single algal cell, they move jointly and cells in an algae colony may cease to exist under any inappropriate nutrient circumstances. An external shear force and any other unsuitable life scenario may disperse the algae colony and every dispersed portion becomes a new algae colony and life continues.

Population of Algal colony $=\left[\begin{array}{ccc}\mathrm{P}_{1}^{1} & \cdots & \mathrm{P}_{1}^{\mathrm{D}} \\ \vdots & \ddots & \vdots \\ \mathrm{P}_{\mathrm{N}_{\mathrm{p}}}^{1} & \cdots & \mathrm{P}_{\mathrm{N}_{\mathrm{p}}}^{\mathrm{D}}\end{array}\right]$

kth algal colony $=\left[\mathrm{P}_{\mathrm{k}}^{1}, \mathrm{P}_{\mathrm{k}}^{2}, \mathrm{P}_{\mathrm{k}}^{3}, \cdots, \mathrm{P}_{\mathrm{k}}^{\mathrm{D}}\right]$ 
The algae colony which exists at an optimal point is called optimum colony and cells it consists of are called optimum cells.

\subsubsection{Evolution:}

Under the appropriate nutrient conditions, if algae colony absorbs sufficient light, it grows in the liquid and mitotic division takes place in which a parent algal cell reproduces itself to produce two identical daughter algal cells. On the other hand, an algae colony which does not obtain sufficient sunlight tries to survive in the environment but dies eventually. Monod model is used to address the growth kinetics of artificial algae colony. The size of ith algae colony at time $(\mathrm{t}+$ 1) can be calculated using the Monod function, as follows:

$\mathrm{S}_{\mathrm{k}}^{\mathrm{t}+1}=\mu_{\mathrm{k}}^{\mathrm{t}} \mathrm{S}_{\mathrm{k}}^{\mathrm{t}}, \quad \mathrm{k}=1,2,3,4, \ldots, \mathrm{N}_{\mathrm{p}}$

where $S_{k}^{t}$ denotes the size of kth colony at time $t$ and $\mathrm{N}_{\mathrm{P}}$ represents the number of algae colonies. Algae colonies providing the most appropriate and cost efficient solutions grow more rapidly because they obtain large amount of nutrients and sunlight. For an individual cell of the tiniest algae colony expiring during the development course, the corresponding cell of largest algae colony takes its place.

Biggest $_{\text {colony }}^{\mathrm{t}}=\operatorname{maximum}\left(\mathrm{S}_{\mathrm{k}}^{\mathrm{t}}\right), \mathrm{k}=1,2,3, \cdots, \mathrm{N}_{\mathrm{p}}$

Smalest $\mathrm{t}_{\text {colony }}^{\mathrm{t}}=\operatorname{minimum}\left(\mathrm{S}_{\mathrm{k}}^{\mathrm{t}}\right), \mathrm{k}=1,2,3, \cdots, \mathrm{N}_{\mathrm{p}}$

Smallest $_{\text {colony }_{\mathrm{r}}}^{\mathrm{t}}=$ Biggest $_{\text {colony }_{\mathrm{r}}^{\mathrm{t}}}^{\mathrm{t}}, \mathrm{r}=1,2,3, \ldots, \mathrm{D}$

where problem dimension is represented by $\mathrm{D}$, Biggest $\mathrm{t}_{\text {colony }}^{\mathrm{t}}$ is the largest algae colony and Smallest $\mathrm{t}_{\text {colony }}^{\mathrm{t}}$ represents the smallest algae colony at time t. In the algorithm, colonies are arranged in order of their sizes. A randomly nominated cell of the most poorly grown colony expires in the evolution process and a corresponding algal cell of largest colony is replicated in its place.

\subsubsection{Adaptation:}

In an environment, insufficiently grown algae colonies attempt to adjust themselves to the surrounding environment and consequently the dominant class alters. In the adaptation process, an inadequately grown algae colony tries to adjust itself according to the surroundings which leads to a change of prevailing species. It tries to attain the same resemblance as that of the fittest (largest) algae colony of the population. The starvation level is subjected to change due to this adaptation. Initially, the starvation level is taken as zero for all colonies and it increases as the time $t$ passes by, when a particular colony does not absorb sufficient sunlight. In this phase, the algae colony having the highest starvation value is adopted according to following equations.

$\operatorname{starve}^{\mathrm{t}}=\operatorname{maximum}\left(A_{\mathrm{k}}^{\mathrm{t}}\right)$

starve $^{t+1}=\operatorname{starve}^{t}+\left(\right.$ biggest $^{t}-$ starve $\left.^{t}\right) \times$ rand

where $A_{\mathrm{k}}^{\mathrm{t}}$ represents the starvation of kth algae colony and starve ${ }^{t}$ is the most starved algal colony of the population at time $t$. Decision if adaptation of colonies will occur at time $t$ or not is made by the adaptation parameter $\left(A_{p}\right)$. Its value is a constant in the interval $[0,1]$.

\subsubsection{Helical Movement Pattern:}

Algae colonies and cells move helically in the fluid with the help of their flagella and they try to exist nearby water surface for their survival because adequate sunlight is available. Forward motion of micro-algae colonies is constrained by viscous-drag force of the liquid and gravity. Algal cell movements are different. As an alga grows in the liquid, its frictional surface gets larger which causes the frequency of helical movement to rise which in turn increases its local search capability. All the algal cells can move in the liquid according to their energy. While energy $E$ of an alga at any time $t$ has a direct relation with the absorption of sunlight and uptake of nutrient at $t$. So, algal cells closer to water surface will have more energy and they can dive more inside the liquid. On the other hand, algal cells far beneath the water 
surface will have smaller size and proportionally less energy but due to their smaller size, frictional surface will be less so their movement distance inside the fluid will be longer. Hence, their global search ability will be more. However, they will be able to cover less distance in the liquid in correlation to their energy.

In the algorithm, gravity which is restricting the forward movement is assumed to be negligible and is taken as zero. While viscous drag, which is presented as a shear force, varies in direct proportion to the frictional surface size of the algal colony. Since colonies are in spherical shape so its size is modeled as volume. Therefore, the surface area of hemisphere gives us the friction surface of the colony.

$$
\begin{aligned}
& \tau\left(P_{k}\right)=2 \pi r^{2} \\
& \tau\left(\mathrm{P}_{\mathrm{k}}\right)=2 \pi\left(\sqrt[a]{\frac{3 \mathrm{~S}_{\mathrm{k}}}{4 \pi}}\right)^{2}
\end{aligned}
$$

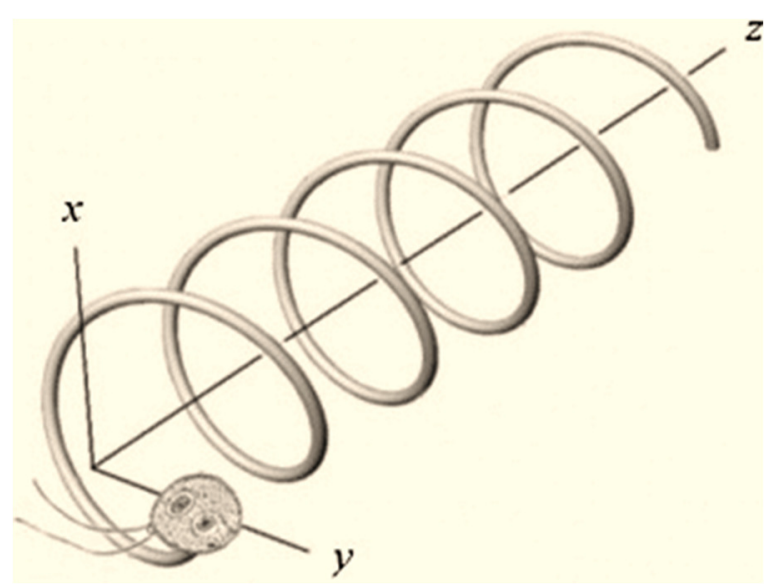

FIG. 2: HELICAL MOVEMENT OF MICROALGAE [30]

For the helical swimming of microalgal cell, three dimensions are chosen randomly. One dimension addresses the linear movement while the other two provide angular movement. Eq. (19) is used in unidirectional problems and algal cell movement is considered to be in straight line. In bidirectional optimization problems, the algal cell movement is considered to be sinusoidal and Eq. (20) are used to address this movement pattern. In the event of three or more dimensional problem, the movement pattern of algal cells is helical, as shown in Fig.2. The step size for each algal colony is determined by its distance from the source of light and frictional surface of the colony.

$\mathrm{P}_{\mathrm{kl}}^{\mathrm{t}+1}=\mathrm{P}_{\mathrm{rl}}^{\mathrm{t}}+\left(\mathrm{P}_{\mathrm{sl}}^{\mathrm{t}}-\mathrm{P}_{\mathrm{tl}}^{\mathrm{t}}\right) \times\left(\Delta-\tau^{\mathrm{t}}\left(\mathrm{P}_{\mathrm{r}}\right)\right) \mathrm{p}$

$\left.\mathrm{P}_{\mathrm{km}}^{\mathrm{t}+1}=\mathrm{P}_{\mathrm{sm}}^{\mathrm{t}}+\left(\mathrm{P}_{\mathrm{tm}}^{\mathrm{t}}-\mathrm{P}_{\mathrm{rm}}^{\mathrm{t}}\right) \times\left(\Delta-\tau^{\mathrm{t}}\right)\left(\mathrm{P}_{\mathrm{s}}\right)\right) \cos \alpha(21)$

$\left.\mathrm{P}_{\mathrm{kn}}^{\mathrm{t}+1}=\mathrm{P}_{t n}^{\mathrm{t}}+\left(P_{r n}^{t}-\mathrm{P}_{\mathrm{sn}}^{\mathrm{t}}\right) \times\left(\Delta-\tau^{\mathrm{t}}\right)\left(\mathrm{P}_{\mathrm{t}}\right)\right) \sin \beta$

where, $\quad \mathrm{k}=1,2,3 \ldots, \mathrm{N}_{\mathrm{P}} ; \mathrm{k} \neq \mathrm{r} \neq \mathrm{s} \neq \mathrm{t} ; \mathrm{l} \neq \mathrm{m} \neq$ $\mathrm{n} ; l, m, n=1,2,3, \ldots D ; \Delta$ represents the shear (i.e. external) force, $\tau^{t}\left(P_{k}\right)$ is the frictional surface area of kth algae colony; $\beta \in[0,2 \pi] \quad ; p \in[-1,1]$. The flowchart of AAA is shown in Fig. 3.

\section{MODELING OF ELD PROBLEM INAAA ENVIRONMENT}

\subsection{Constraint handling methods for ED Problem}

The discussion to follow presents the schemes for the handling of different constraints associated with the ED problem.

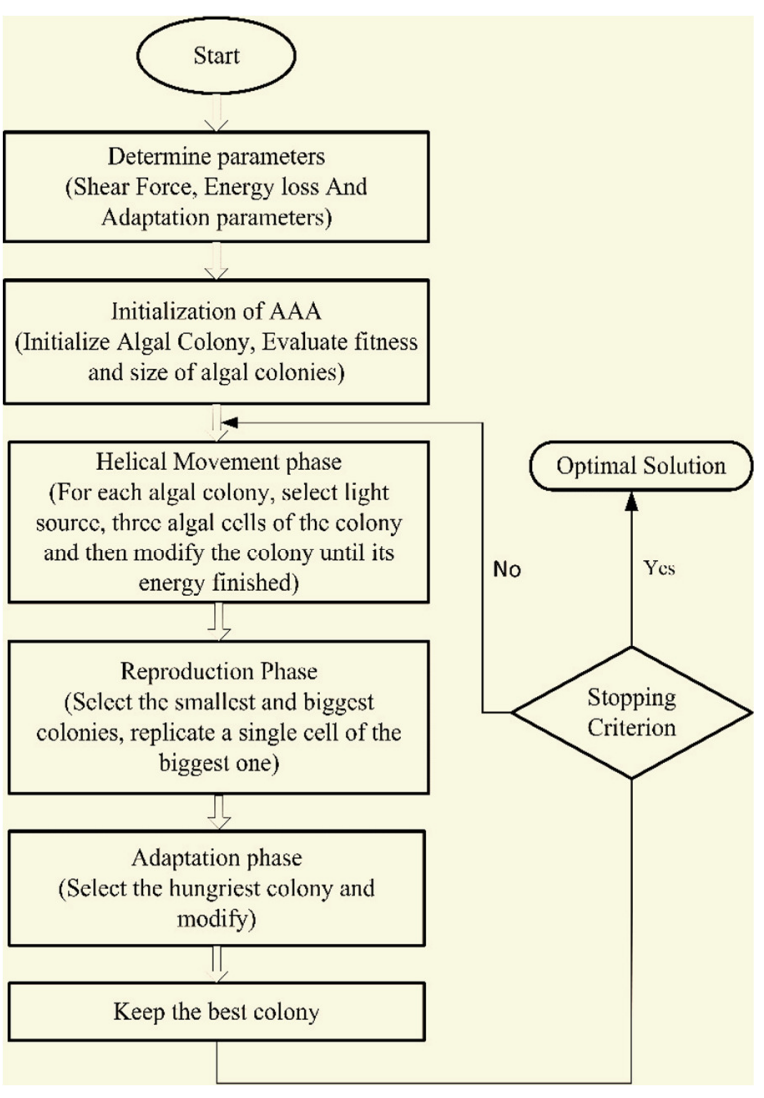

FIG. 3: FLOWCHART OF AAA 


\subsection{Handling of Generation Capacity Limits}

During the search for optimal solution, the generation capacity limits of $j t h$ generator addressed by equation (5) is handled by using the following equation:

$P_{j}=\left\{\begin{array}{cc}P_{j}, \quad\left(P_{j}^{\text {min }} \leq P_{j} \leq P_{j}^{\text {max }}\right) \\ P_{j}^{\text {min }}, \quad\left(P_{j}<P_{j}^{\text {min }}\right) \\ P_{j}^{\text {max }}, \quad\left(P_{j}>P_{j}^{\text {max }}\right) \\ \text { where } j=1,2,3, \cdots, D\end{array}\right.$

\subsection{Handling the Constraint of Power Balance}

To handle the constraint of power balance of ED problem, an iterative repair scheme is used in this paper. First of all, the difference among the generated power and sum of transmission losses and power demand is computed as follows:

$\Delta \mathrm{p}=\mathrm{p}_{\text {Demqand }}+\mathrm{P}_{\mathrm{T}_{-} \text {Loss }}-\sum_{\mathrm{j}=1}^{\mathrm{D}} \mathrm{P}_{\mathrm{j}}$

Now, if $(\Delta \mathrm{P}=0)$, the generated output power is in the feasible generation region and equality constraint is satisfied and solution does not need to go through any repair process. However, if $(\Delta \mathrm{P} \neq 0)$, then generated output power does not meet our demand and transmission losses and the solution needs to be modified. When $(\Delta P>0)$, this implies that $\left(P_{\text {Demand }}+P_{T_{-} \text {Loss }}>\sum_{j=1}^{D} P_{j}\right), \quad$ and $\quad$ the generated power needs to be increased. Similarly, when $\quad\left(\Delta \mathrm{P}_{\mathrm{D}}<0\right), \quad$ then $\left(P_{\text {Demand }}+P_{T_{-} \text {Loss }}<\right.$ $\left.\sum_{j=1}^{D} P_{j}\right)$, and the generated power needs to be decreased. This repair process is illustrated in the following equations:

$P_{j}= \begin{cases}P_{j}+\min \left(\left(P_{j}^{\max }-P_{j}\right) z_{j},\right. & \left.\left(\frac{|\Delta P|}{\sum_{j=1}^{D} P_{j}}\right) P_{j}\right) ; \Delta P>0 \\ P_{j}-\min \left(\left(P_{j}-P_{j}^{m i n}\right) Z_{j},\right. & \left.\left(\frac{|\Delta P|}{\sum_{j=1}^{D} P_{j}}\right) P_{j}\right) ; \Delta P>0\end{cases}$

where $z_{j}$ represents a random numeral between interval $[0,1] ; P_{j}^{\max }(M W)$ and $P_{j}^{\min }(M W)$ are the upper and lower bounds of output power generation for jth generator; and $\mathrm{P}_{\mathrm{j}}(\mathrm{MW})$ is the actual generated power of jth generating unit.

Equation (25) shows that any change in output power is done in accordance with the load demand. Further, this equation uses an iterative approach to modify the output power of generating units and the steps of the repair scheme is inscribed in Algorithm.1. An important feature of this scheme is that it bounds the power generation within the capacity limits of generators during the iterative procedure. An external penalty function is also integrated, along with the above mentioned constraint handling scheme, to handle any violation of the power balance restriction if it still persists. The conventional objective function addressed by equation (1) is integrated with a penalty function as described below.

$F_{c}\left(P_{j}\right)=\left\{\begin{array}{cc}F_{c}\left(P_{j}\right), & \text { if } P_{j} \in F R \\ F_{c}\left(P_{j}\right)+r \Delta P^{2} & \text { otherwise }\end{array}\right.$

where $F R$ represents the feasible region for power output, $r$ denotes a positive and very large number and $\Delta \mathrm{P}$ represents any violation of power balance constraint as indicated by equation (24). Equation (26) indicates that a very large penalty is imposed on the fuel cost $\left(F_{C}\right)$ only when the power generation $\left(P_{j}\right)$, violates the equality constraint, otherwise, there is no penalty on the objective function.

\section{Algorithm 1: Handling of Power Balance \\ Constraint (Repair Scheme)}

1. Read the generated power, $P_{j}(j=1,2,3 \ldots D)$, total load demand $\left(\mathrm{P}_{\mathrm{D}}\right)$, Maximum iterations (MAXIter), Number of generation units (D), upper and lower limits of generating units $\left(\mathrm{UB}_{\mathrm{j}}, \mathrm{LB}_{\mathrm{j}}\right)$, Tolerance (TOL) and $\beta$-coefficient matrix $\left(\beta_{\mathrm{ji}}, \beta_{0 \mathrm{j}}, \beta_{00}\right)$ for the calculation of transmission loss.

2. Set a counter for iteration numbers, (Iter $=0)$.

3. Update the counter: $($ Iter $=$ Iter +1$)$.

4. Calculate the sum of generated power outputs, $\sum_{\mathrm{j}=1}^{\mathrm{D}} \mathrm{P}_{\mathrm{j}}$

5. Evaluate the transmission losses ( $\mathrm{P}_{\mathrm{T}_{-} \text {Loss }}$ ) using equation (6). 
6. Calculate the power difference, $(\Delta \mathrm{P})$, using equation (24).

7. If $(\triangle \mathrm{P} \leq \mathrm{TOL})$; terminate.

8. If $(\Delta \mathrm{P}>0)$, then adjust the output power generation $\left(\mathrm{P}_{\mathrm{j}}\right)$ using equation (25) and use equation (23) to fix any violation in generation capacity limits.

9. If $(\Delta \mathrm{P}<0)$, then again adjust the output power generation $\left(\mathrm{P}_{\mathrm{j}}\right)$ using equation (25) and use equation (23) to fix any violation in generation capacity limits.

10. If (Iter $\leq$ MAXIter), GO TO 3; otherwise terminate.

\subsection{Handling of Prohibited Operating Zones}

For the optimum operation of thermal power generating plants, the power generation is prohibited in some regions called prohibited operating zones of the generators [1]. Whenever, the output power of a generating unit violates these POZ limits, the power generation is regulated heuristically according to the following scheme:

$P_{j}= \begin{cases}P_{j, p z}^{L B}-\left(\frac{P_{j, p z}^{U B}-P_{j, p z}^{L B}}{P_{i, j}^{U}}\right) w & \text { if }\left(Z_{1} \leq Z_{2}\right) \\ P_{j, p z}^{U B}+\left(\frac{P_{j, p z}^{U B}-P_{j, p z}^{L B}}{P_{j, j p z}^{U}}\right) w & \text { otherwise }\end{cases}$

where $\mathrm{Z}_{1}=\left(\mathrm{P}_{\mathrm{j}}-\mathrm{P}_{\mathrm{j}, \mathrm{pz}}^{\mathrm{LB}}\right) ; \quad \mathrm{Z}_{2}=\left(\mathrm{P}_{\mathrm{j}, \mathrm{pz}}^{\mathrm{UB}}-\mathrm{P}_{\mathrm{j}}\right) ; \quad \mathrm{j}=$ $1,2,3 \ldots . \mathrm{D} ; \quad \mathrm{pz}=1,2,3 \ldots . \mathrm{NPZ}_{\mathrm{j}} . \quad \mathrm{P}_{\mathrm{j}, \mathrm{pz}}^{\mathrm{LB}}(\mathrm{MW})$ and $\mathrm{P}_{\mathrm{j}, \mathrm{pz}}^{\mathrm{UB}}(\mathrm{MW})$ are the lower and upper limits of pzth prohibited operating zone of jth generation unit; $w$ is a random numeral in the interval $[0,1] ; \mathrm{P}_{\mathrm{j}}(\mathrm{MW})$ is the generated power of $j$ th generator and $\mathrm{NPZ}_{\mathrm{j}}$ denotes the number of POZs of $j$ th generating unit.

\subsection{Pseudo Code of AAA for ELD Problem}

The discussion to follow presents the pseudo code of AAA for the ED problem.

\footnotetext{
Algorithm.2: AAA for ED problem.

1. Specify parameters of the ED problem i.e. Number of generators $(D)$, load demand $\left(P_{D}\right)$, upper and lower bounds for each generation
}

unit $\left(\mathrm{UB}_{\mathrm{j}}, \mathrm{LB}_{\mathrm{j}}\right)$, fuel cost coefficients $\left(a_{j}, b_{j}, c_{j}, e_{j}, f_{j}\right)$, prohibited operating zones (POZs) of each unit and $\beta-$ coefficient matrix $\left(\beta_{\mathrm{ji}}, \beta_{0 \mathrm{j}}, \beta_{00}\right)$ for calculation of transmission loss.

2. Specify the parameters of the AAA i.e. loss of Energy $(\varepsilon)$, Adaptation probability $\left(A_{P}\right)$, Shear force $(\Delta)$, population size $\left(\mathrm{N}_{\mathrm{P}}\right)$, Maximum number of fitness evaluations (MNFEs).

3. Initialize the size of every algae colony $\left(S_{k}=\right.$ $1 ; \mathrm{k}=1,2,3 \ldots \mathrm{N}_{\mathrm{P}}$ ) and set the starvation value of these colonies at zero $\left(\mathrm{H}_{\mathrm{k}}=0\right)$.

4. Initialize the microalgae colonies with random solutions using the following equation. It keeps the random solutions within the bounds of generator.

$$
\mathrm{x}_{\mathrm{kj}}=\mathrm{LB}_{\mathrm{j}}+\left(\mathrm{UB}_{\mathrm{j}}-\mathrm{LB}_{\mathrm{j}}\right) \times \text { random, }
$$
where $\mathrm{j}=1,2,3 \ldots \ldots \mathrm{D}$ and $\mathrm{k}=1,2,3, \ldots \ldots \mathrm{N}_{\mathrm{P}}$

5. Use Algorithm.1 to regulate the generated power of all the algal cell in feasible generation region and fulfill other inequality and $\mathrm{POZ}$ constraints using equations (23)-(27).

6. Compute the total generation cost, $F_{C}(j)$, corresponding to all algal colonies and identify the best cost, $\mathrm{F}_{\mathrm{C}}^{\mathrm{b}}$, associated with the fittest algae colony $\left(P_{j}^{b} ; j=1,2,3 \ldots N_{P}\right)$.

7. Set a counter for iteration numbers: $(i=0)$

8. Update the counter: $(i=\mathrm{i}+1)$

9. Update the algal colony size matrix, $S_{k}$, using equation (11).

10. Calculate energy $\left(\mathrm{E}_{\mathrm{k}}(\mathrm{i})\right)$ of the algae colonies from their sizes (S) using:

$$
\mathrm{E}_{\mathrm{k}}^{\mathrm{i}+1}=\left[\operatorname{norm}\left(\operatorname{rank}\left(\mathrm{S}_{\mathrm{k}}^{\mathrm{i}}\right)\right)^{2}\right]
$$

11. Calculate the frictional surface, $\left(\tau^{\mathrm{k}}(\mathrm{i})\right)$ of each algae colony using equation (19).

12. Set a counter for population(agents) number: $(\mathrm{k}=0)$.

13. Update the population number : $(\mathrm{k}=\mathrm{k}+1)$.

14. Setup a starvation level flag: $(\mathrm{IH}=0)$.

15. While (Algae_Energy $\left(E_{k}\right)>0$ )

16. Select a colony among the population by using tournament selection method. 
17. Choose three unique algal cells $\left(\mathrm{P}_{1}^{\mathrm{k}}, \mathrm{P}_{\mathrm{m}}^{\mathrm{k}}, \mathrm{P}_{\mathrm{n}}^{\mathrm{k}}\right)$ of selected $\mathrm{k}^{\text {th }}$ algae colony in such a way that $(l \neq m \neq n)$.

18. Choose three distinct light sources $(r \neq s \neq t)$ by using tournament selection method for the three selected algae cells $(\mathrm{l}, \mathrm{m}, \mathrm{n})$ of $\mathrm{k}^{\text {th }}$ algal colony.

19. Implement the helical movement and modify the colony using the equations (20)-(22) and decrease energy of the colony, $E_{k}(i)$, caused by the movement of algal cells using:

$\mathrm{E}_{\mathrm{k}}(\mathrm{i})=\mathrm{E}_{\mathrm{k}}(\mathrm{i})-\frac{\varepsilon^{\mathrm{i}}}{2}$

20. Use Algorithm.1 to regulate the updated power of every algal cell in feasible generation region and fulfill other inequality and POZ constraints using equations (23)-(27).

21. Evaluate and compare the updated solution, if updated cost is less than the old cost, then move the algae colony to a new position, update the cost function value and the starvation flag $(\mathrm{IH}=1)$; else reduce energy of the colony, $\mathrm{E}_{\mathrm{j}}(\mathrm{t})$, caused by the metabolism process using equation described in Step 19.

22. End the while loop.

23. If an algal colony does not produce good solution $(\mathrm{IH}=0)$, then increase its starvation value, $\left(\mathrm{H}_{\mathrm{k}}=\mathrm{H}_{\mathrm{k}}+1\right)$.

24. Now If $\left(k<N_{P}\right)$ then move back to step 13; otherwise move forward to step 25 .

25. Update the fittest (i.e. best) algae colony $\left(\mathrm{P}_{\mathrm{j}}^{\mathrm{b}}\right)$ and the algal size matrix, $S_{k}$ of all colonies using equation (11) and select the smallest and biggest algal colonies.

26. Replace a randomly chosen cell of smallest algae colony with the corresponding cell of biggest colony using equation (12)-(14).

27. Update the fittest algae colony $\left(\mathrm{P}_{\mathrm{j}}^{\mathrm{b}}\right)$ among the population.

28. If (rand $\left.(0,1)<A_{p}^{i}\right)$ then implement the adaptation of algae colonies using equation (16)-(17) and update the best generation $\left(\mathrm{P}_{\mathrm{j}}^{\mathrm{b}}\right)$.

29. Perform exploitation of the search space in the proximity of best algae colony $\left(\mathrm{P}_{\mathrm{i}}^{\mathrm{b}}\right)$ and use Algorithm.1 to regulate the generated power of all the algal cell in feasible generation region and fulfill other inequality and POZ constraints using equations (23)-(27).

30. If (NFE< MNFEs) than go to 8; otherwise terminate.

\section{CASE STUDIES}

In order to assess the performance of AAA for solving the Economic Load Dispatch (ELD) problem, it is implemented on 5 IEEE standard test systems and the results are analyzed. MATLAB R2016a is used to implement all the case studies on an Intel corei3, $2.40 \mathrm{GHz}$ with 4GB RAM. 20 independent trials are conducted to evaluate average, best and worst fuel costs because of the probabilistic nature of AAA. These test system are described in the following sections.

\subsection{Case Study 1}

This test system consists of three generation units with total load demand of $850 \mathrm{MW}$. All the test system data which include the fuel cost coefficients, lower and upper limits for the generating units and power demand are taken from [31].

AAA requires a fine tuning of its parameters to converge to global optimum. These parameters are set as follows: Energy loss, $e-0.3$, probability of adaptation, $A_{p}-0.5$ and shear force, $\Delta-2$. In FIG. 4 , the convergence characteristics of generators fuel cost against number of iterations is plotted. The curve shows that AAA converges very quickly towards the global optimum in the initial iterations.

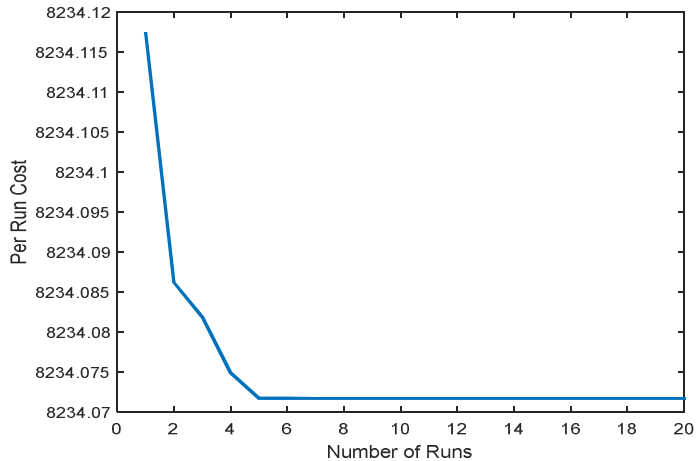

FIG. 4: CONVERGENCE CURVE OF 3 UNIT TEST $\operatorname{SYSTEM}\left(\mathrm{P}_{\mathrm{d}}=850 \mathrm{MW}\right)$ 
The optimum results achieved by the proposed AAA approach is compared with other competitive methods in terms of generation fuel cost, average execution time and standard deviation (SD) and are summarized in Table 1. AAA does not use the memory while selecting a light source. However, AAA compensates this disadvantage by gradually approaching the source of light with the helical movement of algal colonies and through their evolution and adaptation phase. This feature enables the AAA to provide results that are optimum.

\subsection{Case Study 2}

This test system consists of six generation units with convex cost curves. The constraints of transmission losses, POZs and valve point loading effects are also taken into account. The control parameters for this system is set as follows: Energy loss, $e-0.02$, probability of adaptation, $A_{p}-0.7$ and shear force, $\Delta-2$. The load demand of this system is 1263MW. All the related test system data is applied from [35]. In FIG. 5, the convergence characteristics of generators fuel cost against number of iterations is plotted. The convergence characteristic shows that AAA approached the global optimal very systematically by escaping the local minima.

The optimum generators loading corresponding to best trial is recorded in appendix in Table A1. The optimum fuel cost along with transmission losses, average CPU time and standard deviation achieved by the proposed AAA approach is compared with other competitive methods in Table 2. It can be concluded from these tables that AAA provides the competitive results in terms of fuel cost, standard deviation and execution time. It is also observed from the algorithm that smaller values of energy leads to faster convergence.

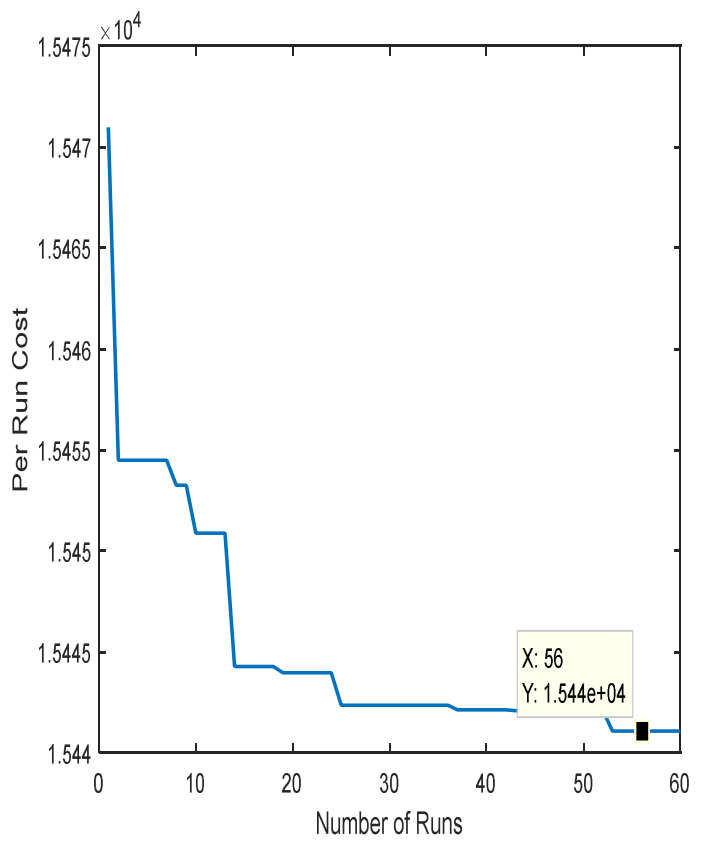

FIG. 5: CONVERGENCE CURVE OF 6 UNIT TEST $\operatorname{SYSTEM}\left(\mathrm{P}_{\mathrm{d}}=1263 \mathrm{MW}\right)$

\subsection{Case Study 3}

This is a 13 unit system with 1800 MW load demand. The test system data is obtained from [31]. The total numbers of trials. The control parameters for this system is set as follows: Energy loss, $e-0.002$, probability of adaptation, $A_{p}-0.8$ and shear force, $\Delta-2$. The convergence curve for this system is presented in FIG. 6.

TABLE 1: COMPARISON OF RESULTS FOR TEST CASE 1

\begin{tabular}{|c|c|c|c|c|c|c|}
\hline \multirow[t]{2}{*}{ Algorithm } & \multicolumn{3}{|c|}{ Individual Generation } & \multirow{2}{*}{$\begin{array}{c}\text { Total } \\
\text { Generating } \\
\text { Cost } \\
(\$ / \mathrm{hr})\end{array}$} & \multirow{2}{*}{$\begin{array}{l}\text { CPU Time } \\
\text { (Sec) }\end{array}$} & \multirow[t]{2}{*}{$\mathrm{SD}$} \\
\hline & $\mathrm{P}_{1}$ & $\mathrm{P}_{2}$ & $\mathrm{P}_{3}$ & & & \\
\hline $\begin{array}{c}\text { GA-PS-SQP } \\
{[10]}\end{array}$ & 300.300 & 400 & 149.700 & 8234.10 & 1.282 & - \\
\hline SDE [12] & 301.678 & 400 & 148.321 & 8241.59 & - & - \\
\hline NTHS [14] & 300.267 & 400 & 149.733 & 8234.07 & - & - \\
\hline$\beta \mathrm{HC}[31]$ & 300.267 & 400 & 149.733 & 8234.07 & 1.701 & 3.061 \\
\hline AAA & 300.267 & 400 & 149.733 & 8234.07 & 0.235 & 1.004 \\
\hline
\end{tabular}


TABLE 2: COMPARISON OF RESULTS FOR TEST CASE 2

\begin{tabular}{|c|c|c|c|c|c|c|c|}
\hline \multirow[t]{2}{*}{ Algorithm } & \multirow{2}{*}{$\begin{array}{l}\text { Total } \\
\text { Power } \\
\text { (MW) }\end{array}$} & \multirow{2}{*}{$\begin{array}{l}P_{\text {loss }} \\
(\mathrm{MW})\end{array}$} & \multicolumn{3}{|c|}{ Total Generating Cost $(\$ / \mathrm{hr})$} & \multirow{2}{*}{$\begin{array}{l}\text { CPU Time } \\
(\mathrm{sec})\end{array}$} & \multirow[t]{2}{*}{ SD } \\
\hline & & & Min. Cost & Max. Cost & Avg. Cost & & \\
\hline DE-IR [7] & 1275.829 & 12.829 & $15,442.72$ & $15,442.72$ & $15,442.72$ & 0.400 & 0.000 \\
\hline $\begin{array}{l}\text { PSO-WPF } \\
{[8]}\end{array}$ & 1275.412 & 12.412 & $15,442.66$ & $15,442.66$ & $15,442.66$ & 0.770 & 0.000 \\
\hline MFO [13] & 1275.42 & 12.422 & $15,444.19$ & - & - & - & - \\
\hline $\begin{array}{l}\text { HBB-BC } \\
{[15]}\end{array}$ & 1275.570 & 12.570 & $15,444.26$ & $15,448,89$ & $15,466.46$ & - & 1.52 \\
\hline IGWO [24] & 1275.312 & 12.312 & $15,442.20$ & $15,442.67$ & $15,442.60$ & - & 0.123 \\
\hline CBA [27] & 1275.985 & 12.985 & $15,450.24$ & $15,518.65$ & $15,454.76$ & 0.704 & 2.965 \\
\hline MCSA [36] & 1275.958 & 12.958 & $15,449.89$ & $15,449.89$ & $15,449.89$ & 0.259 & 0.000 \\
\hline $\begin{array}{l}\text { AMKMTOA } \\
{[37]}\end{array}$ & 1275.204 & 12.282 & $15,441.22$ & $15,442.30$ & $15,445.26$ & 0.025 & 0.782 \\
\hline $\begin{array}{l}\text { JAYA- } \\
\text { SML[38] }\end{array}$ & 1275.335 & 12.335 & $15,445.16$ & $15,450,65$ & $15,447.29$ & 2.110 & 6.221 \\
\hline AAA & 1275.427 & 12.427 & $15,440.39$ & $15,442.48$ & $15,441.37$ & 0.388 & 0.634 \\
\hline
\end{tabular}

Table A2 in appendix presents the generator loadings corresponding to best trial. The optimum fuel cost along with transmission losses, average CPU time and standard deviation achieved by the proposed AAA approach is compared with other competitive methods in Table 3. The convergence characteristics shows that AAA is a competitive approach in the ELD domain. The parameter of energy loss controls the number of new potential candidates that are generated during each iteration due to mitotic division of parent algal cells. It was observed that a smaller initial value of the parameter of energy loss increases the exploitation ability of the AAA but it may lead to premature convergence and local optima stagnation. On the other hand, the higher this parameter is, the higher the global search ability of the algorithm but it slows down the convergence rate of the AAA algorithm. Therefore, AAA requires a fine tuning of this parameter to achieve the optimized results.

\subsection{Case Study 4}

This is also a 13 unit system with load demand of 2520 MW. The test system data is obtained from [31]. The total numbers of trials are 20 while each trial had 60 iterations. The convergence curve in FIG. 7 shows the best trial curve. The optimum generators loading corresponding to best trial is recorded in appendix in Table A3. The optimum results achieved by the proposed AAA approach is compared with other competitive methods in Table 4. The standard deviation and average computational time of AAA for test system under consideration is also given in the Table. The adaptation parameter $\left(A_{p}\right)$, basically

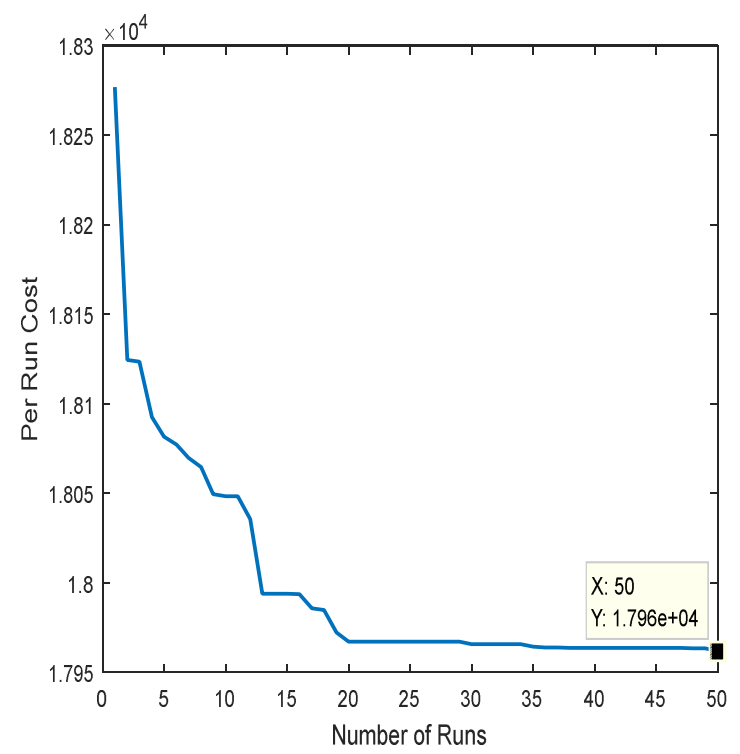

FIG. 6: CONVERGENCE CURVE OF 13 UNIT TEST $\operatorname{SYSTEM}\left(\mathrm{P}_{\mathrm{d}}=1800 \mathrm{MW}\right)$

regulates the speed with which the algal colonies, which are unable to find the fit solutions, adapts themselves to the environment. It was observed that a large value of the adaptation parameter increases the convergence rate and hence computational time and production cost reduces. 


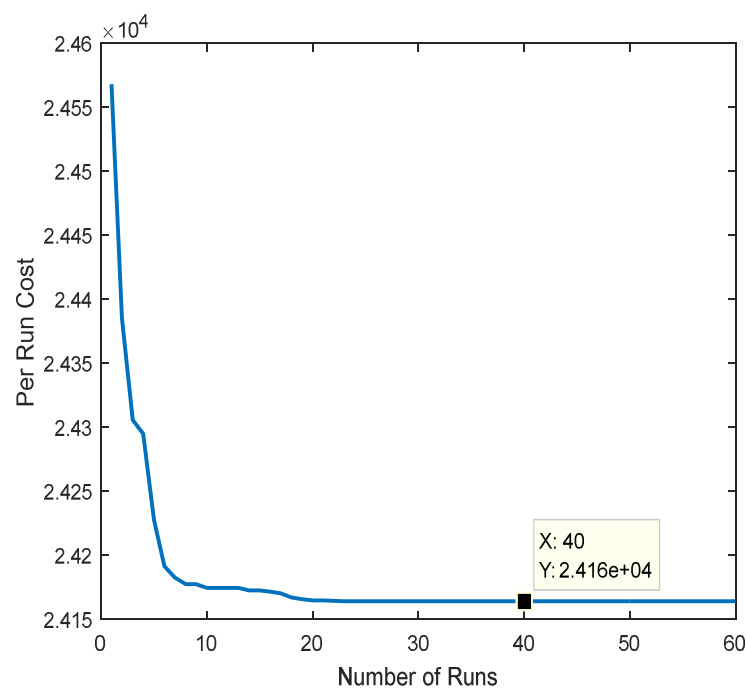

FIG. 7: CONVERGENCE CURVE OF 13 UNIT TEST SYSTEM $\left(\mathrm{P}_{\mathrm{D}}=2520 \mathrm{MW}\right)$
Table 4 presents a comparison of the AAA results with recent evolutionary approaches for the 13 Unit test System. It is clear that the proposed AAA obtains the minimum fuel cost, similar to nine of the comparative methods.

\subsection{Case Study 5}

In this case study, a large test system of 40 generation units with valve point effects is considered. Total power demand of this system is $10500 \mathrm{MW}$. The related test system data is taken from [31]. FIG. 8 shows the smooth convergence of AAA for this large system. The control parameters for this system is set as follows: Energy loss, e -0.002 , probability of adaptation, $A_{p}-0.8$ and shear force, $\Delta-2$. Table A4 is appendix shows the optimized dispatch values for 40 generators.

TABLE 3: COMPARISON OF RESULTS FOR TEST CASE 3

\begin{tabular}{|c|c|c|c|c|c|}
\hline \multirow{2}{*}{ Algorithm } & \multicolumn{3}{|c|}{ Total Generating Cost $(\$ / \mathrm{hr})$} & \multirow{2}{*}{ CPU Time (Sec.) } & \multirow{2}{*}{ SD } \\
\cline { 2 - 4 } & Min. Cost & Max. Cost & Avg. Cost & & \\
\hline MABC [9] & $17,963.82$ & $17,963.82$ & $17,963.82$ & - & 0.000 \\
\hline QOSL TLBO [16] & $18,421.17$ & 18.031 .00 & $17,994.67$ & 4.582 & - \\
\hline CKH [17] & $17,961.99$ & $17,968.22$ & $17,965.33$ & 3.772 & 0.874 \\
\hline MSOS [22] & $17,963.83$ & $17,963.82$ & $17,963.82$ & 0.811 & 0.000 \\
\hline HCRO-DE [25] & $17,960.38$ & $17,961.04$ & $17,960.59$ & 5.230 & - \\
\hline CBA [27] & $17,963.83$ & $17,995.22$ & $17,965.49$ & 0.972 & 6.847 \\
\hline BHC [31] & $17,960.41$ & $18,132.06$ & $17,988.60$ & - & 16.97 \\
\hline AMKMTOA [37] & $17,960.11$ & $17,964.74$ & $17,961.78$ & 0.641 & 0.906 \\
\hline GWO [39] & $17,974.22$ & $18,031.00$ & $17,994.67$ & 4.271 & 4.671 \\
\hline AIS [40] & $17,972.81$ & $17,999.56$ & $17,986.18$ & - & - \\
\hline AAA & $17,960.37$ & $17,969.49$ & $17,967.92$ & 3.540 & 0.754 \\
\hline
\end{tabular}

TABLE 4: COMPARISON OF RESULTS FOR TEST CASE 4

\begin{tabular}{|c|c|c|c|c|c|}
\hline \multirow{2}{*}{ Algorithm } & \multicolumn{3}{|c|}{ Total Generating Cost (\$/hr) } & \multirow{2}{*}{ CPU Time (Sec.) } & \multirow{2}{*}{ SD } \\
\cline { 2 - 4 } & Min. Cost & Max. Cost & Avg. Cost & & \\
\hline MABC [9] & $24,169.91$ & $24,169.91$ & $24,169.91$ & - & 0.000 \\
\hline NTHS [14] & $24,164.06$ & - & $24,201.10$ & 5.710 & - \\
\hline CKH [17] & $24,164.18$ & $24,166.11$ & $24,168.43$ & 4.550 & 0.667 \\
\hline THS [23] & $24,164.06$ & - & $24,185.21$ & 3.951 & 30.20 \\
\hline IGWO [24] & $24,202.16$ & $24,228.35$ & $24,210.00$ & 4.582 & 7.021 \\
\hline BHC [31] & $24,164.18$ & $24,232.06$ & $24,204.90$ & - & 31.27 \\
\hline MCSA [36] & $24,169.92$ & $24,169.92$ & $24,169.92$ & 1.722 & 0.000 \\
\hline Jaya-SML [38] & $24,169.90$ & $24,285.89$ & $24,217.08$ & 2.453 & - \\
\hline CGAC [41] & $24,170.04$ & $24,190.97$ & $24,181.31$ & - & - \\
\hline AAA & $24,164.05$ & $24,168.81$ & $24,175.07$ & 3.940 & 0.874 \\
\hline
\end{tabular}


TABLE 5: COMPARISON OF RESULTS FOR TEST CASE 5

\begin{tabular}{|c|c|c|c|c|c|}
\hline \multirow{2}{*}{ Algorithm } & \multicolumn{3}{|c|}{ Total Generating Cost $\$$ /hr) } & \multirow{2}{*}{ CPU Time (Sec.) } & \multirow{2}{*}{ SD } \\
\cline { 2 - 4 } & Min. Cost & Max. Cost & Avg. Cost & & \\
\hline NTHS [14] & 121412.73 & - & 121459.95 & - & - \\
\hline HBB-BC [15] & 121471.72 & 122137.42 & 121984.24 & 16.52 & - \\
\hline CKH [17] & 121412.75 & 121412.90 & 121412.84 & 1.780 & 0.0758 \\
\hline CTLBO [21] & 121553.83 & 122116.18 & 121790.23 & 4.830 & 150.00 \\
\hline CBA [27] & 121412.54 & 121436.15 & 121418.98 & 1.550 & 1.6110 \\
\hline OLCSO [29] & 121415.81 & 121504.04 & 121460.77 & 47.24 & 21.799 \\
\hline BHC [31] & 121414.68 & - & 121496.84 & 7.940 & 53.704 \\
\hline MCSA [36] & 121412.53 & 121421.12 & 121414.16 & 3.990 & 2.7456 \\
\hline AMKMTOA [37] & 121411.56 & 121416.60 & 121413.25 & 1.446 & 1.4864 \\
\hline JAYA-SML [38] & 121476.39 & 122039.87 & 121689.07 & 12.89 & 147.89 \\
\hline AGWO [42] & 121403.90 & 121464.80 & 121424.00 & 2.432 & 7.5040 \\
\hline AAA & 121409.17 & 121436.15 & 121430.12 & 4.361 & 3.3644 \\
\hline
\end{tabular}

The comparison between the optimum fuel cost obtained by AAA and other latest evolutionary algorithms is presented in Table 5. It is obvious from the table that AAA produced balanced and successful results. Balanced local and global search qualifications allow AAA to produce results near to global optimum.

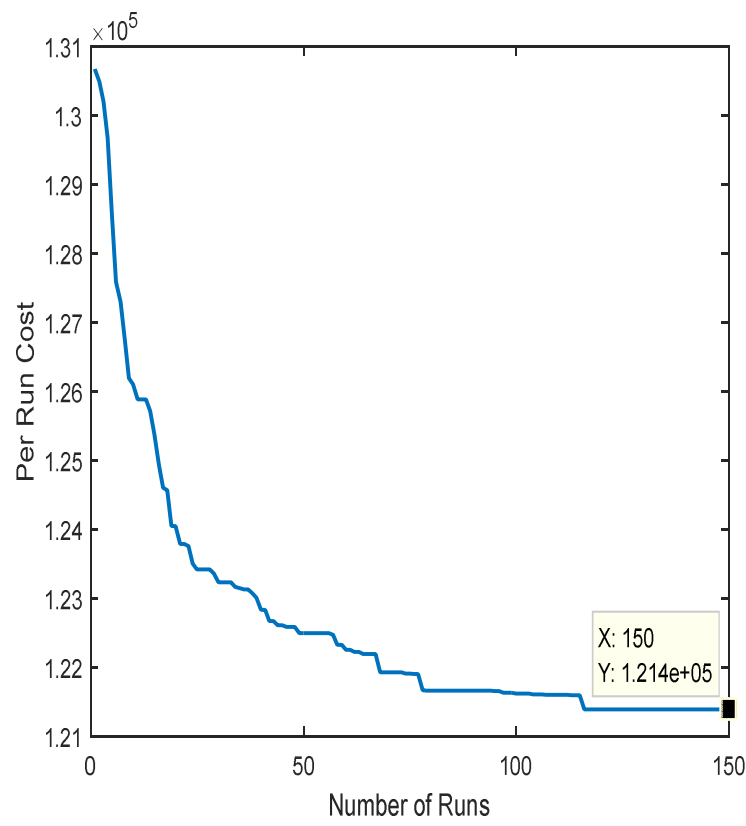

FIG. 8: CONVERGENCE CHARACTERISTIC OF 40 UNIT TEST SYSTEM $\left(P_{d}=10500 M W\right)$

The ability to balance local and global search contributes to success of AAA. Light source selection on the basis of updated information for this large test system reduces the risk of local optima stagnation. The success and efficacy of AAA is reflected in its smooth convergent behavior and its speed. For all the test systems under considerations, AAA delivers the optimized results. It is also a fast, robust and stable algorithm as it provides shorter computational time and lower standard deviation.

\section{CONCLUSION:}

This paper uses a novel, highly efficient meta-heuristic approach called AAA for solving the ED problem. AAA is a population based evolutionary optimization algorithm. It is based on mimicking the natural living behavior of algae. Basically, the microalgae model has been developed by employing the property of an algal cell to be close to sunlight, its helical movement pattern and features of reproduction and adaptation to the surrounding environment. In the algorithm, an algae colony is assumed to be an individual candidate searching for optimum solutions continuously within the search space.

AAA has basically three control parameters (shear force, energy loss and adaptation parameter) and two basic operators (evolutionary and adaptation process). In adaptation phase, an insufficiently grown algae colony tries to resemble itself to the largest algae colony of the search space in each iteration. While In evolutionary phase, a single cell of smallest algae colony dies and corresponding algae cell of the largest colony replaces its position. This process provides 
fine-tuning to achieve the global optimum. New candidate solutions are produced by the application of helical movement of algae. In AAA, the step size is calculated by the weighted difference between a solution chosen with tournament selection and the current solution. AAA uses a greedy selection approach to choose between the current and new candidate solution.

The performance of AAA was accessed by implementing it on 5 IEEE standard test systems for solving the Economic Load Dispatch (ELD) problem. The results are then compared with the most recent evolutionary approaches and AAA is found to be a consistent and balanced algorithm. The main drawback of AAA is its large number of parameters which require fine tuning to achieve global optimum compared to other algorithms. Inappropriate parameter values may lead to premature convergence and local optima stagnation.

AAA requires further hybrid studies and parameter tuning to increase the rate of convergence and achieve better optimum solutions. In addition, it can be extended to address the multi area ED problem with multiple fuel options (MFO) and dynamic power system operational studies. AAA is highly sensitive to its parameters so adaptive version of AAA can be proposed to enhance its performance. Future research can be oriented to considering other constraints and making improvements in presented results. Practical engineering optimization problems can also be solved using AAA.

\section{ACKNOWLEDGEMENT}

The authors wish to acknowledge the support from Ph.D. and M.Sc. Graduates, Department of Electrical Engineering, University of Engineering \& Technology, Taxila, Pakistan. The authors gratefully acknowledge the University of Engineering \& Technology, Taxila, Pakistan, for providing support to carry out this research work.

\section{REFERENCES}

[1] A. J. Wood and B. F. Wollenberg, "Power
Generation, Operaion, and control," John Wiley \& Sons Inc., Chapter 03, pp. 29-45, 1996.

[2] Anwar, Z., Malik, T. N., and Abbas, T., "Power Flow and Transient Stability Enhancement using Thyristor Controlled Series Compensation," Mehran University Research Journal of Engineering and Technology, Volume 37, No. 4, pp. 685-700, October, 2018.

[3] Zhan, J.P., Wu, Q.H., Guo, C.X., and Zhou, X.X., "Fast lambda-Iteration Method for Economic Dispatch With Prohibited Operating Zones," IEEE Transactions on Power System, Volume 29, No. 2, pp. 990991, March, 2014.

[4] Li, Z., Wu, W., Zhang, B., Sun, H., and Guo, Q., "Dynamic economic dispatch using Lagrangian relaxation with multiplier updates based on a quasi-Newton method," IEEE Transactions on Power System, Volume 28, No. 4, pp. 4516-4527, June, 2013.

[5] Fan, J., and Zhang, L., "Real-time economic dispatch with line flow and emission constraints using quadratic programming," IEEE Transactions on Power System, Volume 13, No. 2, pp. 320-325, May, 1998.

[6] Irisarri, G., Kimball, L. M., Clements, K. A., Bagchi, A., and Davis, P. W., "Economic dispatch with network and ramping constraints via interior point methods," IEEE Transactions on Power System, Volume 13, No. 1, pp. 236-242, February, 1998.

[7] Li, X., Xiao, C., and Lu, Z., “A New Constraint Handling Method for Economic Dispatch," Journal of Electrical Engineering \& Technology, Volume. 13, No. 3, pp. 10991109, May, 2018.

[8] Ghorbani, N., Vakili, S., and Sarkhosh, A., "A new coding for solving large-scale nonconvex economic dispatch problems without a penalty factor," International Journal of Management Science and Engineering Management, Volume. 12, No. 4, pp. 256268, October, 2017.

[9] Secui, D. C., "A new modified artificial bee colony algorithm for the economic dispatch 
problem," Energy Conversion and Management, Volume 89, No. 1, pp. 43-62, January, 2015.

[10] Alsumait, J. S., Sykulski, J. K., and AlOthman, A. K., "A hybrid GA-PS-SQP method to solve power system valve-point economic dispatch problems," Applied Energy, Volume 87, No. 5, pp. 1773-1781, May, 2010.

[11] Zou, D., Li, S., Li, Z., and Kong, X., “A new global particle swarm optimization for the economic emission dispatch with or without transmission losses," Energy Conversion and Management, Volume 139, No. 1, pp. 45-70, May, 2017

[12] Chandrakala, G., Ramakrishna, V., and Shaik, J. B., "Solving economic dispatch with valve point loading effects by using optimization techniques," International Journal of Engineering Science Invention, Volume 3, No. 9, pp. 01-011, September, 2014.

[13] Rehman, K., and Ahmed, A., "A Novel Hybrid Moth Flame Optimization with Sequential Quadratic Programming Algorithm for Solving Economic Load Dispatch Problem," Mehran University Research Journal of Engineering and Technology, Volume. 38, No. 1, pp. 129-142, January, 2019.

[14] Al-Betar, M. A., Awadallah, M. A., Khader, A. T., Bolaji, A. L., and Almomani, A., "Economic load dispatch problems with valve-point loading using natural updated harmony search," Neural Computing and Applications, Volume 29, No. 10, pp. 767781, May, 2018.

[15] Labbi, Y., and Attous, D. Ben, “A Hybrid Big Bang-Big Crunch optimization algorithm for solving the different economic load dispatch problems," International Journal of System Assurance Engineering and Management, Volume. 8, No. 2, pp. 275-286, June, 2017.

[16] Prakash, T., Singh, V. P., Singh, S. P., and Mohanty, S. R., "Economic load dispatch problem: quasi-oppositional self-learning TLBO algorithm," Energy Systems, Volume 9, No. 2, pp. 415-438, May, 2018.
[17] Bentouati, B., Chettih, S., and El-Sehiemy, R. A.-A., "A Chaotic Krill Herd Algorithm for Optimal Solution of the Economic Dispatch Problem," International Journal of Engineering Research in Africa, Volume 31, pp. 155-168, July, 2017.

[18] Haroon, S. S., and Malik, T. N., "Short Term Economic Emission Power Scheduling of Hydrothermal Energy Systems Using Improved Water Cycle Algorithm," Mehran University Research Journal of Engineering and Technology, Volume 37, No. 2, pp. 255272, April, 2017.

[19] Adil, S. H., Raza, K., and Hashmani, M. A., "A Hybrid Cuckoo Algorithm for Lot Scheduling Problem Using Extended Basic Period and Power of Two Policy," Mehran University Research Journal of Engineering and Technology, Volume. 35, No. 2, pp. 229238, July, 2016.

[20] Massan, S.-R., Wagan, A. I., and Shaikh, M. M., "A New Hybrid Metaheuristic Algorithm for Wind Farm Micrositing," Mehran University Research Journal of Engineering and Technology, Volume 36, No. 3, pp. 635648, July, 2017.

[21] He, X., Rao, Y., and Huang, J., "A novel algorithm for economic load dispatch of power systems," Neurocomputing, Volume 171, pp. 1454-1461, January, 2016.

[22] Secui, D. C., "A modified Symbiotic Organisms Search algorithm for large scale economic dispatch problem with valve-point effects," Energy, Volume 113, pp. 366-384, October, 2016.

[23] Al-Betar, M. A., Awadallah, M. A., Khader, A. T., and Bolaji, A. L., "Tournament-based harmony search algorithm for non-convex economic load dispatch problem," Applied Soft Computing, Volume 47, pp. 449-459, October, 2016.

[24] Mehmood, K., and Ahmed, A., "Improved Grey Wolf Optimization for Economic Load Dispatch Problem Considering Valve Point Loading Effect and Prohibited Operating Zones," The Nucleus, Volume 54, No. 4, pp. 250-257, February, 2018. 
[25] Roy, P. K., Bhui, S., and Paul, C., "Solution of economic load dispatch using hybrid chemical reaction optimization approach," Applied Soft Computing, Volume 24, pp. 109-125, November, 2014.

[26] Han, L., Romero, C. E., and Yao, Z., "Economic dispatch optimization algorithm based on particle diffusion," Energy Conversion and Management, Volume 105, pp. 1251-1260, November, 2015.

[27] Adarsh, B. R., Raghunathan, T., Jayabarathi, T., and Yang, X.-S., "Economic dispatch using chaotic bat algorithm," Energy, Volume 96, pp. 666-675, February, 2016.

[28] Basu, M., "Kinetic gas molecule optimization for nonconvex economic dispatch problem," International Journal of Electrical Power \& Energy Systems, Volume 80, pp. 325-332, September, 2016.

[29] Xiong, G., and Shi, D., “Orthogonal learning competitive swarm optimizer for economic dispatch problems," Applied Soft Computing, Volume 66, pp. 134-148, May, 2018.

[30] Uymaz, S.A., Tezel, G., and Yel, E., "Artificial algae algorithm (AAA) for nonlinear global optimization," Applied Soft Computing, Volume 31, pp. 153-171, June, 2015.

[31] Al-Betar, M., Awadallah, M., Doush, I.A., Alsukhni, E., Alkhraisat, H., "A Non-convex Economic Dispatch Problem with Valve Loading Effect Using a New Modified $\beta$-Hill Climbing Local Search Algorithm," Arabian Journal for Science and Engineering, Volume 43, No. 12, pp. 1-18, February, 2018.

[32] Salih, F. M., "Microalgae Tolerance to High Concentrations of Carbon Dioxide: A Review," Journal of Environmental Protection, Volume 02, No. 05, pp. 648-654, July, 2011.

[33] Curtis, T. P., Mara, D. D., Dixo, N. G. H., and Silva, S. A., "Light penetration in waste stabilization ponds," Water Research, Volume 28, No. 5, pp. 1031-1038, May, 1994.

[34] Grima, E. M., Camacho, F. G., Pérez, J. A. S., Sevilla, J. M. F., Fernández, F. G. A., and Gómez, A. C., "A mathematical model of microalgal growth in light-limited chemostat culture," Journal of Chemical Technology and Biotechnology, Volume. 61, No. 2, pp. 167173, October, 1994.

[35] Al Bahrani, L. T., and Patra, J. C., "Orthogonal PSO algorithm for Economic Dispatch of Thermal Generating Units Under Various Power Constraints in Smart Power Grid," Applied Soft Computing, Volume 58, pp. 401-426, September, 2017.

[36] Zhao, J., Liu, S., Zhou, M., Guo, X. and Qi, L., "Modified Cuckoo Search Algorithm to Solve Economic Power Dispatch Optimization Problems," IEEE/CAA Journal of Automatica Sinica, Volume. 5, No. 4, pp. 794-806, July, 2018.

[37] Fan, C., Li, J., Yi, L., Xiao, L., Zhu, B., and Ren, K., "An Optimal Algorithm Based on Kinetic-Molecular Theory with Artificial Memory to Solving Economic Dispatch Problem." Current Science, Volume 115, No. 3, pp. 454-464, August, 2018.

[38] Yu, J., Kim, C.-H., Wadood, A., Khurshaid, T., and Rhee, S.-B., "Jaya Algorithm With Self-Adaptive Multi-Population and Lévy Flights for Solving Economic Load Dispatch Problems," IEEE Access, Volume 7, pp. 21372-21384, February, 2019.

[39] Pradhan, M., Roy, P. K., and Pal, T., "Grey wolf optimization applied to economic load dispatch problems," International Journal of Electrical Power \& Energy Systems, Volume. 83, pp. 325-334, December, 2016.

[40] Kumar, S.P., Vijay, R., and Satish, G., "Performance Analysis of Evolutionary Optimization Techniques for Economic Dispatch Problem," International Journal of Advances in Computer and Electronics Engineering, Volume 4, No. 2, pp. 6-16, February, 2019.

[41] Mishra, R., and Das, K. N., "Chemo-Inspired GA for Non-convex Economic Load Dispatch," Soft Computing for Problem Solving, Volume 2, pp. 843-856, October, 2019.

[42] Singh, D., and Dhillon, J. S., "Ameliorated Grey Wolf Optimization for Economic Load 
Dispatch Problem" Energy, Volume 169, pp. 398-419, February, 2019.

\section{APPENDIX}

TABLE A1: OPTIMAL GENERATIONS FOR TEST CASE 2

\begin{tabular}{|c|c|c|c|c|}
\hline $\begin{array}{l}\text { Unit } \\
\text { No. }\end{array}$ & $\begin{array}{c}\mathbf{P}_{\min } \\
(\mathrm{MW})\end{array}$ & $\begin{array}{l}\mathbf{P}_{\max } \\
(\mathrm{MW})\end{array}$ & $\begin{array}{l}\text { Generation } \\
\text { (MW) }\end{array}$ & $\begin{array}{c}\text { Fuel cost } \\
(\$ / \mathrm{hr} .)\end{array}$ \\
\hline 1. & 100 & 500 & 446.7171 & 4763.09 \\
\hline 2. & 50 & 200 & 173.1548 & 2216.40 \\
\hline 3. & 80 & 300 & 262.7959 & 3075.30 \\
\hline 4. & 50 & 150 & 143.4912 & 1962.70 \\
\hline & 50 & 200 & 163.9148 & 2155.00 \\
\hline 6. & 50 & 120 & 85.35422 & 1267.90 \\
\hline \multicolumn{3}{|c|}{ Total } & 1275.4277 & 15440.39 \\
\hline \multicolumn{3}{|c|}{ Transmission losses } & 12.4277 & \\
\hline
\end{tabular}

TABLE A2: OPTIMAL GENERATIONS FOR TEST CASE 3

\begin{tabular}{|c|c|c|c|c|}
\hline $\begin{array}{c}\text { Unit } \\
\text { No. }\end{array}$ & $\begin{array}{c}\mathbf{P}_{\min } \\
(\mathbf{M W})\end{array}$ & $\begin{array}{l}\mathbf{P}_{\max } \\
(\mathbf{M W})\end{array}$ & $\begin{array}{c}\text { Generation } \\
(\mathbf{M W})\end{array}$ & $\begin{array}{c}\text { Fuel cost } \\
\mathbf{( \$ / h r})\end{array}$ \\
\hline 1 & 0 & 680 & 628.318 & 5749.90 \\
\hline 2 & 0 & 360 & 224.398 & 2154.80 \\
\hline 3 & 0 & 360 & 297.549 & 2777.10 \\
\hline 4 & 60 & 180 & 60.0000 & 716.064 \\
\hline 5 & 60 & 180 & 60.0000 & 716.064 \\
\hline 6 & 60 & 180 & 109.866 & 1129.50 \\
\hline 7 & 60 & 180 & 60.0000 & 716.064 \\
\hline 8 & 60 & 180 & 109.866 & 1129.50 \\
\hline 9 & 60 & 180 & 60.0000 & 716.064 \\
\hline 10 & 40 & 120 & 40.0000 & 474.554 \\
\hline 11 & 40 & 120 & 40.0000 & 474.554 \\
\hline 12 & 55 & 120 & 55.0000 & 607.591 \\
\hline 13 & 55 & 120 & 55.0000 & 607.591 \\
\hline & & & $\mathbf{1 8 0 0}$ & $\mathbf{1 7 9 6 0 . 3 7}$ \\
\hline
\end{tabular}

TABLE A4: OPTIMAL GENERATIONS FOR TEST CASE 5

\begin{tabular}{|c|c|c|c|c|c|c|c|c|c|}
\hline $\begin{array}{l}\text { Unit } \\
\text { No. }\end{array}$ & $\begin{array}{l}P_{\min } \\
(\mathrm{MW})\end{array}$ & $\begin{array}{l}P_{\max } \\
\text { (MW) }\end{array}$ & $\begin{array}{l}\text { Generation } \\
\text { (MW) }\end{array}$ & $\begin{array}{l}\text { Fuel cost } \\
(\$ / \mathrm{hr} .)\end{array}$ & $\begin{array}{l}\text { Unit } \\
\text { No. }\end{array}$ & $\begin{array}{l}P_{\min } \\
\text { (MW) }\end{array}$ & $\begin{array}{l}P_{\max } \\
\text { (MW) }\end{array}$ & $\begin{array}{c}\text { Generation } \\
\text { (MW) }\end{array}$ & $\begin{array}{c}\begin{array}{c}\text { Fuel cost } \\
(\$ / \mathrm{hr} .)\end{array}\end{array}$ \\
\hline 1 & 36 & 114 & 110.7998 & 925.096 & 21 & 254 & 550 & 523.2793 & 5061.30 \\
\hline 2 & 36 & 114 & 110.7998 & 925.096 & 22 & 254 & 550 & 523.2792 & 5061.30 \\
\hline 3 & 60 & 120 & 120.0000 & 1544.70 & 23 & 254 & 550 & 523.2793 & 5067.20 \\
\hline 4 & 80 & 190 & 179.7333 & 2043.60 & 24 & 254 & 550 & 523.2794 & 5057.20 \\
\hline 5 & 47 & 97 & 87.79990 & 706.500 & 25 & 254 & 550 & 523.2793 & 5275.10 \\
\hline 6 & 68 & 140 & 140.0000 & 1596.50 & 26 & 254 & 550 & 523.2794 & 5275.10 \\
\hline 7 & 110 & 300 & 299.8777 & 3276.30 & 27 & 10 & 150 & 10.00000 & 1140.50 \\
\hline 8 & 135 & 300 & 284.5997 & 2779.80 & 28 & 10 & 150 & 10.00000 & 1140.50 \\
\hline 9 & 135 & 300 & 284.5995 & 2798.20 & 29 & 10 & 150 & 10.00000 & 1140.50 \\
\hline 10 & 130 & 300 & 130.0000 & 2502.10 & 30 & 47 & 97 & 87.80030 & 706.260 \\
\hline 11 & 94 & 375 & 243.5994 & 4023.20 & 31 & 60 & 190 & 190.0000 & 1644.00 \\
\hline 12 & 94 & 375 & 168.7995 & 2977.50 & 32 & 60 & 190 & 190.0000 & 1644.00 \\
\hline 13 & 125 & 500 & 214.7596 & 3792.10 & 33 & 60 & 190 & 190.0000 & 1644.00 \\
\hline 14 & 125 & 500 & 214.7596 & 4005.70 & 34 & 90 & 220 & 220.0000 & 2228.40 \\
\hline 15 & 125 & 500 & 394.2794 & 6136.60 & 35 & 90 & 220 & 220.0000 & 2164.50 \\
\hline 16 & 125 & 500 & 304.5192 & 5071.20 & 36 & 90 & 220 & 220.0000 & 2164.50 \\
\hline 17 & 220 & 500 & 489.2793 & 5296.70 & 37 & 25 & 110 & 110.0000 & 1220.20 \\
\hline 18 & 220 & 550 & 550.0000 & 6215.10 & 38 & 25 & 110 & 110.0000 & 1220.20 \\
\hline 19 & 242 & 550 & 511.2793 & 5540.90 & 39 & 25 & 110 & 110.0000 & 1220.20 \\
\hline 20 & 242 & 550 & 331.7598 & 3636.40 & 40 & 242 & 550 & 511.2790 & 5540.90 \\
\hline \multicolumn{3}{|c|}{ Total Demand(MW) } & \multicolumn{2}{|c|}{$\frac{1}{10500}$} & \multicolumn{4}{|c|}{ Total Fuel Cost $(\$ / h r)$} & ,409.17 \\
\hline
\end{tabular}


TABLE A3: OPTIMAL GENERATIONS FOR TEST CASE 4

\begin{tabular}{|c|c|c|c|c|}
\hline $\begin{array}{c}\text { Unit } \\
\text { No. }\end{array}$ & $\begin{array}{c}\mathbf{P}_{\min } \\
(\mathbf{M W})\end{array}$ & $\begin{array}{c}\mathbf{P}_{\max } \\
(\mathbf{M W})\end{array}$ & $\begin{array}{c}\text { Generation } \\
(\mathbf{M W})\end{array}$ & $\begin{array}{c}\text { Fuel cost } \\
\mathbf{( \$ / h r )}\end{array}$ \\
\hline 1 & 0 & 680 & 628.3185 & 5749.900 \\
\hline 2 & 0 & 360 & 299.1993 & 2782.600 \\
\hline 3 & 0 & 360 & 294.6480 & 2770.400 \\
\hline 4 & 60 & 180 & 159.7331 & 1559.000 \\
\hline 5 & 60 & 180 & 159.7331 & 1559.000 \\
\hline 6 & 60 & 180 & 159.7331 & 1559.000 \\
\hline 7 & 60 & 180 & 159.7330 & 1559.000 \\
\hline 8 & 60 & 180 & 159.7331 & 1559.000 \\
\hline 9 & 60 & 180 & 159.7331 & 1559.000 \\
\hline 10 & 40 & 120 & 77.39965 & 808.6526 \\
\hline 11 & 40 & 120 & 77.39954 & 808.6528 \\
\hline 12 & 55 & 120 & 92.39984 & 944.8859 \\
\hline 13 & 55 & 120 & 92.39966 & 944.8864 \\
\hline & Total & & $\mathbf{2 5 2 0}$ & $\mathbf{2 4 1 6 4 . 0 5}$ \\
\hline
\end{tabular}

